\title{
MARCAS NA SUBJETIVIDADE DO TRABALHADOR
} CONTEMPORÂNEO

\author{
Traits In The Subjectivity Of The Contemporary Worker \\ Rasgos En La Subjetividad Del Trabajador Contemporáneo \\ Les Marques De La Subjectivité Du Travailleur Contemporain
}

Rute Andrade Santos ${ }^{1}$

Mestre em Desenvolvimento Regional - UFT Especialista em Administração Estratégica: Ênfase em Gestão de Pessoas - UFSJ Graduada em Psicologia, com Licenciatura - UFJS

Franciele Monique Scopetc dos Santos ${ }^{2}$ Doutora em Educação Escolar - Universidade Estadual Paulista UNESP/Araraquara Mestra em Educação Para o Ensino de Ciências e a Matemática -UEM

Licenciada em Filos ofia - UEM

Professora Assistente da Universidade Federal do Maranhão, Campus VII/Codó

\section{RESUMO}

Este artigo objetiva investigar como a subjetividade do trabalhador contemporâneo é marcada pelas novas relações de trabalho provenientes do modelo flexível econômico. Este se fundamenta na nova forma flexível de acumulação do capital. Discussões a respeito da disseminação do capitalismo e da nova ética do trabalho serão apresentados, e para dialogar com a teoria apresenta-se como objeto de investigação a pesquisa com trabalhadores de uma empresa privada do estado do Tocantins. Como método de pesquisa utilizou-se a análise qualitativa e a investigação social, realizando 12 entrevistas com os sujeitos sociais pesquisados. Como resultado, concluiu-se a necessidade de entendimento do regime econômico vigente e suas formas de capturar o trabalhador contemporâneo, provocando marcas profundas em sua subjetividade.

Palavras-Chave: Subjetividade, Trabalhador Contemporâneo, Flexibilização

\begin{abstract}
This article aims to investigate how the subjectivity of the contemporary worker is traced by the new labor relations coming from the flexible economic model. This is based on the new flexible form of accumulation of capital. Discussions regarding the dis semination of the "new spirit of capitalism" and the new work ethic will be presented. In order, it is presented as an object of investigation research about workers of private company of the state of Tocantins. As a research method, qualitative analysis and the social research. 12 interviews with the social subjects surveyed were realized. As a result, we conclude the need to understand the current economic regime and its ways of capturing the contemporary worker, provoking profound marks on his subjectivity.
\end{abstract}

Keywords: Subjectivity, Contemporary Worker, Flexibilization

\footnotetext{
${ }^{1}$ E-mail: ruteras1@gmail.com

${ }^{2}$ E-mail: franmonique@gmail.com
} 


\section{RÉSUMÉ}

Cet article vise à étudier la subjectivité du travail contemporaine est marquée par les nouvelles relations de travail du modèle économique souple. Le modèle est basé sur la nouvelle forme flexible d'accumulation du capital. Les discussions surla diffusion de «nouvel esprit du capitalisme » et la nouvelle éthique de travail seront présentés. Elle est présentée comme un objet de la recherche entreprise privée chez les travailleurs etat Tocantins. En tant que méthode de recherche utilisée l'analyse qualitative et la recherche sociale, mener 12 entretiens avec les sujets sociaux interrogés. En conséquence de la recherche a conclu la nécessité d'une compréhension du système économique actuel et les moyens de capturer le travailleur contemporain, ce qui provoque des traces profondes dans leur subjectivité.

Mots-Clés: Subjectivité, Travailleur contemporain, Approche flexible.

\section{RESUMEN}

Este artículo tiene por objetivo investigar cómo la subjetividad del trabajador contemporáneo está marcada por las nuevas relaciones de trabajo provenientes del modelo flexible económico. Este se fundamenta en la nueva forma flexible de acumulación del capital. Las discusiones sobre la diseminación del "nuevo espíritu del capitalismo" y de la nueva ética del trabajo se presentarán. Se presenta como objeto de investigación trabajadores de empresa privada de estado de los Tocantins. Como método de investigación se utilizó el análisis cualitativo y la investigación social, realizando 12 entrevistas con los sujetos sociales investigados. Como resultado de la investigación se concluye la necesidad de entendimiento del régimen económico vigente y sus formas de capturar al trabajador contemporáneo, provocando marcas profundas en su subjetividad.

Palabras-Clave: Subjetividad, Trabajador Contemporáneo, Flexibilización

\section{INTRODUÇÃO}

Este artigo tem por objetivo investigar como a subjetividade do trabalhador contemporâneo é marcada pelas novas relações de trabalho. Para efeito, busca explanar e exemplificar como o modelo econômico flexível reflete na subjetividade e nos comportamentos sociais do trabalhador contemporâneo. O modelo econômico flexível se fundamenta na nova forma flexível de acumulação do capital que se deu em confronto ao Fordismo (Harvey, 1996). Este estudo se fundamenta nos autores Birman (2012), Boltanski e Chiapello (2009), Sennet (2009) e Weber (1967) os quais tratam da temática favorecendo a análise do momento atual em que vive $o$ trabalhador na sociedade contemporânea.

Para dialogar com a teoria, apresenta-se como objeto de investigação a pesquisa realizada com trabalhadores de uma empresa privada, presente no estado do Tocantins desde 1989, mas que após intervenção federal, passou a ser assumida por um novo grupo acionário de base nacional. Em 2014 esse novo grupo obteve a concessão do Governo Federal para dar seguimento à prestação de serviço de necessidade pública para população do estado do Tocantins. Esta análise apresenta uma contribuição às pesquisas relacionadas as dinâmicas do trabalho, uma vez que este é um campo de estudos em efervescência no norte do Brasil.

Porém, antes de prosseguir com os teóricos apresentados acima, uma apropriação do conceito de subjetividade faz-se necessário. Não se tem a intenção de exaurir este conceito neste escrito, mas oferecer um suporte teórico sobre o tema a ser desenvolvido. Dessa feita, apropria-se do conceito de subjetividade trazido por Ewald e Soares (2007, p. 35), o qual descreve sua origem grega, traduzida para o latim subiectum, sendo traduzida como "a noção do que é fundamental e que permanece subjacente".

Ewald e Soares (2007) citam Merleau-Ponty (1962) para clarificar esse conceito, trazendo a subjetividade como a conciliação dos extremos do homem em sua consciência individual e o pensamento geral, sendo o fundamento da identidade social e individual. A subjetividade, ainda 
com a contribuição dos autores citados, é a capacidade de receber e dar sentido a algo. "Chamarei subjetividade a capacidade de receber o sentido, de fazer algo com ele e de produzir sentido, dar sentido, fazer com que cada vez seja um sentido novo" (Ewald \& Soares, 2007, p. 35).

A construção da subjetividade pode ser entendida a partir das representações das vivências e experiências de um sujeito

[...] individual e socialmente construída, é determinada e determinante das ressignificações e dos sentidos de ação, ao mesmo tempo em que é instituída e instituinte dessas ressignificações. Ela é definida pela dinâmica existente entre biografia e a história, mediada pela noção de experiência (Cardoso, 2007, p. 34).

Após essa explanação sobre o conceito de subjetividade, o caminho para a reflexão sobre a temática proposta estará mais fundamentado dando suporte para iniciar questões tais como: Quem é esse sujeito social contemporâneo, A nova ética do trabalho e o sofrimento psíquico do trabalhador.

\section{Quem é esse sujeito social da contemporaneidade}

Caracterizar o sujeito social da era contemporânea é transitar pelos conceitos disseminados pelas ideologias sociais dominantes, as quais partem por um processo de inculcação nesses sujeitos mencionados através de dispositivos empresariais. Na obra A ética protestante e o espírito do capitalismo, Weber (1967) discute que o espírito do capitalismo foi altamente difundido pelas igrejas protestantes da época. Observa-se que essa ideologia reflete até os dias atuais na subjetividade desse sujeito social, dirigindo sua ação e seu comportamento.

A visão de mundo que se tinha na idade moderna era que a finalidade da vida deveria ser o trabalho. Essa visão se assentou na expressão paulina "Quem não trabalha não deve comer" (Weber, 1967, p. 113). O trabalho passou a ser visto como necessário à sobrevivência individual e coletiva. A garantia da vida eterna difundida pelo Calvinismo se dava a partir da confiança em Cristo, desde que a fé fosse provada por resultados objetivos, assim se teria a base segura para salvação. A ideia disseminada pelo protestantismo na prática é que Deus ajuda quem se ajuda, assim se confere nos aportes de Weber (1967).

A ideologia capitalista se fortaleceu através dos discursos Calvinistas e de seus seguidores como: a perda de tempo, o tempo necessário ao sono de $6 \mathrm{~h}$ a $8 \mathrm{~h}$ diárias no máximo, a vida ociosa. Para difundir a necessidade do trabalho, discursos fomentavam a ideia de que esses fatores distanciavam o homem da glorificação. Esse tipo de discurso disseminado nas igrejas protestantes da época de Calvino foi introjetado pelos sujeitos sociais criando a partir desse, uma relação com o trabalho. Uma relação de subsunção do homem ao trabalho. Assim, a ideia de um trabalho racional e sistematizado foi imbricada nos discursos religiosos, os quais reforçavam a ideia da necessidade do homem buscar se qualificar e ter um ofício certo para que não caísse em "perdição" (Weber, 1967).

Outro pensamento disseminado também que corroborou fortemente com a formação da subjetividade do sujeito moderno foi a forma que as igrejas protestantes viam a riqueza, uma vez que a condição de estar em pobreza era vista como não amar ao próximo. A ideia difundida era que Deus abençoa aqueles que souberam aproveitar as oportunidades. Oportunidades essas que podem ser entendidas, na lógica capitalista, como a realização do trabalho.

Esses discursos ideológicos só vieram reforçar a máxima do capitalismo, a ideia do self made man, aquele que se realiza pelos próprios méritos. A ética protestante difundida era não desfrutar espontaneamente a vida. A sociedade 
capitalista tende a proteger quem quer trabalhar contra a classe do proletariado e do sindicato (Weber, 1967). Com a transformação do capitalismo até o século passado, esses conceitos ganharam força cada vez mais através das instituições religiosas e também educacionais, de maneira a reforçar a ideia de a finalidade da vida ser o trabalho para o homem ganhar a sua sobrevivência. Cabe lembrar, mesmo que as igrejas protestantes passando por crises de identidade entre os seus fiéis, sua máxima permaneceu inabalável proliferando fortemente a teoria da prosperidade nos dias atuais ${ }^{3}$.

Diante disso, o sujeito social contemporâneo, mesmo não sendo seguidor desse tipo de religião ou credo, capta em sua subjetividade essa máxima disseminada pelas igrejas e instituições educacionais. Essa disseminação aparece embutida nos sinais e símbolos do cotidiano da sociedade discutida através dos discursos e dos meios de comunicação, formando assim uma crença de quem é o "homem ideal" (Weber, 1967) nessa nova sociedade.

Além das disseminações protestantes, outro fator que contribuiu para o fortalecimento e perpetuação do capitalismo foi o regime econômico "acumulação flexível" ocorrido na década de 1970, conforme Harvey (1996). Este regime provocou grandes transformações sociais e culturais na sociedade que refletem até os dias de hoje. A urgência do tempo, a liquidez dos valores, a mudança constante, o consumo desenfreado, a flexibilidade total, todos esses comportamentos são marcas simbólicas dessa nova sociedade. Esse sujeito social, o qual está inserido nessa sociedade, vivencia esse novo tempo repleto de surpresas e incertezas, no qual grande parte dos símbolos e signos que o direcionavam desapareceram.

\footnotetext{
3 Teoria da prosperidade - "Conjunto de doutrinas e ritos responsável, em parte, pelo crescimento das igrejas neopentecostais, que desencadearam no pentecostalismo surpreendentes mudanças axiológicas, estéticas, nos padrões de comportamento e no relacionamento destes
}

São essas imprevisibilidades que desorientam esse sujeito, virando a subjetividade de ponta a cabeça, tanto no âmbito individual/local quanto coletivo/global (Birman, 2012). Esse sujeito se sente perdido. É um momento marcado pela ausência total de uma referência e Birman (2012) o denomina como o "malestar na atualidade". É o momento onde o sujeito não tem mais a possibilidade de experenciar, é a ausência de possibilidades, inexistência de um futuro previsível.

Birman (2012) refere-se à sociedade contemporânea como a sociedade do espetáculo, resgatando o enunciado de Debord. A sociedade do espetáculo é marcada por laços sociais frágeis, na qual esses se restringem ao campo da imagem e do espetáculo. Essa nova forma de sentir e vivenciar o mundo dá um novo tom para a subjetividade desse sujeito social. Um sujeito marcado pelo "ter" para apresentar à uma plateia em forma de espetáculo, na qual acredita-se que será aplaudido. Possuir é regra imperativa. Ter bens representa poder e status de um indivíduo (Birman, 2012).

Essa nova subjetividade é o casamento perfeito para obsolescência programada e o consumismo desenfreado disseminado pelo modelo econômico flexível. 'É pelo princípio do fetichismo da mercadoria, a sociedade sendo dominado por coisas "suprassensíveis embora sensíveis", que o espetáculo se realiza absolutamente" (Debord, 2003, p. 29). Assim, a subjetividade desse sujeito social contemporâneo é capturada pelas formas de inclusão e exclusão desse sistema flexível estruturando uma nova forma de "malestar". Ter "é um signo que confere segurança para o indivíduo, pois o faz acreditar ser detentor de algum poder pelo status que pode exibir" (Birman, 2012, p. 94). Assim, essas formas de consumis mo

religiosos com a sociedade, dissolvendo suas já tradicionais características de religião sectária e ascética" (Mariano, 1996, p. 26). 
são amplamente assentadas em um discurso cooptador.

A estrutura do novo mercado de trabalho obrigou esse sujeito social a direcionar a sua existência como um ser extremamente flexível perdendo seu eixo principal, ou seja, a sua identidade (Sennett, 2009). A regra fundamental para esse sujeito social contemporâneo é procurar sua sobrevivência e adaptar às oscilações do mercado, segundo Sennett (2009). Pode se reforçar essa compreensão com o próprio Manual de Saúde, o qual destaca que o trabalho é o integrador social em que reflete questões na subjetividade e na saúde do trabalhador.

Em nossa sociedade, o trabalho é mediador de integração social, seja por seu valor econômico (subsistência), seja pelo aspecto cultural (simbólico), tendo, assim, importância fundamental na constituição da subjetividade, no modo de vida e, portanto, na saúde física e mental das pessoas. A contribuição do trabalho para as alterações da saúde mental das pessoas dá-se a partir de ampla gama de aspectos: desde fatores pontuais, como a exposição a determinado agente tóxico, até a complexa articulação de fatores relativos à organização do trabalho, como a divisão e parcelamento das tarefas, as políticas de gerenciamento das pessoas e a estrutura hierárquica organizacional. Os transtornos mentais e do comportamento relacionados ao trabalho resultam, assim, não de fatores isolados, mas de contextos de trabalho em interação com o corpo e aparato psíquico dos trabalhadores. As ações implicadas no ato de trabalhar podem atingir o corpo dos trabalhadores, produzindo disfunções e lesões biológicas, mas também reações psíquicas às situações de trabalho patogênicas, além de poderem desencadear processos psicopatológicos especificamente relacionados às condições do trabalho desempenhado pelo trabalhador (Brasil, 2001, p. 161).

Enfim, a subjetividade do sujeito social contemporâneo tem sua formação calcada nos princípios éticos da sociedade flexível ancorada no regime da acumulação flexível e na ideologia disseminada pelas instituições. Essas instituições mobilizam o sujeito para o movimento de um engajamento à adaptação das oscilações do mercado flexível. Assim poderemos apresentar que as instituições trouxeram uma nova ética do trabalho para o trabalhador contemporâneo.

\section{A Nova Ética do trabalho e o sofrimento psíquico do trabalhador}

A nova ética do trabalho advém da ideologia discutida por Weber (1967) quando esse faz referências ao ascetismo e o puritanismo como forma de ganhar o céu, aliados ao espírito e a pressão do capitalismo para "excelência" profissional, traço da nova ética do trabalho.

A nova ética profissional neste novo cenário é marcada pela autodisciplina do tempo e o trabalho em equipe favorável ao modelo econômico flexível. Trabalho em equipe pode ser visto como superficial e aparente, segundo Sennett (2009), uma vez que as relações no ambiente de trabalho se tornam performáticas. Porém, o discurso o qual propõe o caminho à plenitude profissional prevalece, a busca contínua por tais comportamentos.

A moderna ética do trabalho concentra-se no trabalho de equipe. Celebra a sensibilidade aos outros; exige "aptidões delicadas", como ser bom ouvinte e cooperativo; acima de tudo, o trabalho em equipe enfatiza a adaptabilidade às circunstâncias. $\mathrm{O}$ trabalho de equipe é a ética de trabalho que serve a uma economia 
política flexível. Apesar de todo o arquejar psicológico da administração moderna sobre o trabalho de equipe no escritório e na fábrica, é o etos de trabalho que permanece na superfície da experiência. $\mathrm{O}$ trabalho de equipe é a prática de grupo da superficialidade degradante (Sennett, 2009, p. 118).

Como as equipes mudam constantemente nesse regime flexível, a característica de trabalhar em equipe se torna transitória. As equipes são formadas de acordo com os projetos, é a era dos projetos, das redes (Boltanski \& Chiapello, 2009). Os trabalhadores se reúnem enquanto equipe simplesmente para executar um projeto, sem a necessidade de uma identificação entre si, apenas a necessidade de realização do projeto. A utilização da cooperação do trabalho em equipe tem como objetivo velado a garantia do emprego e a não exclusão ao mercado. É "uma espécie de "teatro profundo" porque obriga os indivíduos a viver de acordo com as aparências, de maneira a manipular o seu comportamento com os outros (Sennett, 2009).

O trabalho em equipe, a autodisciplina, o empreendedorismo, como demais práticas ditadas pelo mercado de trabalho são utilizadas na atualidade para capturar o sujeito trabalhador para se engajar nos novos projetos. As empresas utilizam de técnicas que trabalham com entusiasmo e que despertam uma crença no trabalhador que eles estejam fazendo aparentemente de modo voluntário.

Ora, esses dispositivos, que assentam no consentimento e na adesão, só podem atingir seu objetivo se moldados segundo figuras típicas de uma gramática da autenticidade: a gramática das relações espontâneas e amistosas, da confiança, do pedido de ajuda ou de conselho, da atenção ao mal-estar ou ao sofrimento, da simpatia e até do amor. Aqueles que se encontram envolvidos nesses dispositivos não podem recusar-se categoricamente a participar dessas trocas (o que os levaria diretamente ao esquecimento ou à demissão) nem ignorar (nem mesmo nos momentos nos quais participam dessas trocas sem segundas intenções ou até com prazer) que essas relações mais "autênticas" estão associadas a técnicas de "mobilização" (como dizem Crozier e Sérieyx [1994@J], para se distinguirem bem das antigas formas "infantilizadoras" de "motivação", que já não exercem "nenhum fascínio sobre pessoas altamente escolarizadas" (Boltanski \& Chiapello, 2009, p. 465).

As empresas atuais praticam fidedignamente este princípio e investe $m$ cada vez mais em treinamentos que dizem promover tais práticas. Esse é o mercado que foi criado para grandes empresas de consultorias, treinamentos com preços altíssimos vistos como forma de investimento pelas empresas. Treinamentos desde dinâmicas de grupos mais tradicionais até os mais ousados com enfretamento de desafios na natureza como técnica para desenvolver a superação e os limites do trabalhador.

As empresas de consultoria organizacional no Brasil tiveram um crescimento de mais de $20 \%$ nos anos 2000. Este crescimento chamou atenção da classe empresarial brasileira, uma vez que chegaram a faturar mais de 100 bilhões de dólares nesse período, de acordo com Donadone (2005). Essas empresas de consultorias e de treinamentos são grandes aliadas do capitalismo e servem para inculcar o novo espírito do capitalismo na sociedade através de um discurso de libertação. A atuação do Serviço Brasile iro de Apoio às Micro e Pequenas Empresas (Sebrae) é um exemplo deste tipo de inculcação já que esta instituição fomenta o capitalis mo com suas práticas que tendem a atender $\mathrm{o}$ interesse da classe dominante 
(Menchise, 2014). As empresas de consultorias levam "a sério a vocação do capitalismo para mercantilizar o desejo, especialmente o de libertação e assim cooptá-lo e enquadrá-lo" (Boltanski \& Chiapello, 2009, p. 440).

Outra característica fundamental da nova ética profissional é a disciplina do controle do tempo, de acordo com Birman (2012). Porém, essa disciplina é vivenc iada como um paradoxo, já que tudo é urgente e imediato. A necessidade de entregar um resultado dentro do tempo estipulado obriga o trabalhador a oferecer mais do seu tempo para empresa a fim de não se sentir culpado pela não entrega de um projeto acordado. Esse paradoxo gera um sofrimento no trabalhador. Mas para não ter que lidar com esse sentimento, esse sujeito social busca justificativas na sua própria responsabilização pela disciplina do controle do tempo.

De acordo com Birman, (2012), há nessa nova ética uma valorização da contração do tempo, do curto prazo e do imediatismo. O tempo passa a ter caráter de urgência e tudo passa com essa nova ética, inclusive os profissionais e suas carreiras que já não existem mais. A valorização do tempo era algo valorizado na sociedade moderna em que o sujeito vivenciava a sua subjetividade em um eterno presente acreditando que a repetição era a garantia de estabilidade eterna. $\mathrm{O}$ tempo não mais pode ser eterno, o tempo urge. Surge a concepção de não ter tempo, o homem contemporâneo não tem mais tempo. O tempo sumiu.

A noção de tempo se alterou na sociedade contemporânea com o novo planejamento do trabalho a partir do influxo das mulheres pobres no mundo do trabalho e, por conseguinte da entrada das mulheres da classe média, apontado por Sennett (2009). O novo planejamento do tempo não segue mais uma linha contínua e parte para uma desorganização da rotina. É a lei do curto prazo, do imediatismo, uma corrida contra o tempo. É a flexibilização do tempo. A subjetividade, então com esse novo planejamento, vai ser refletida na ideia do "homem ideal" (Weber, 1967) dessa sociedade, ser o homem que não tem tempo ou que ocupa o seu tempo todo em função do trabalho. Este é o trabalhador "ideal".

O tempo flexível aparece fortemente nas relações de trabalho atuais. O discurso do empreendedorismo ganha força, já que o próprio trabalhador faz o seu próprio negócio, no seu tempo, nas horas de almoço e aos finais de semana e ou em casa, os chamados home-offices para vendedores ou profissionais da área de comunicação. Mecanismos tais como ferramentas de trabalho que aparentemente demonstram um status, como smartphones, computadores, carros os mais modernos possíveis, oferecem uma conectividade de $24 \mathrm{~h}$ com o trabalho, ratificando o reinado da urgência do tempo.

Sennett (2009) afirma que o trabalhador contemporâneo, para se manter nesse novo mundo, tem que se adaptar a esse novo dinamismo do tempo. O discurso flexível mobiliza o trabalhador para a busca de uma plenitude profissional. Ele tem que ser flexível, adaptar-se e correr risco. Tais narrativas provocam desapego ao passado e às suas raízes. Assim, sua identidade é moldada de acordo com o tipo de trabalho em que passa a servir, características do mundo dos projetos, das redes, conforme Boltanski e Chiapello (2009). Um mundo em que a empregabilidade passa a ser os projetos e não mais um único local de trabalho.

Ressalta-se atentar para esse tipo de relação com o trabalho que o controle, mesmo à distância, continua. Apenas mudou a forma de submissão a esse.

Um trabalhador em flexitempo controla o local do trabalho, mas não adquire maior controle sobre o processo de trabalho em si. A essa altura, vários estudos sugerem que a supervisão do trabalho muitas vezes é na verdade maior para os ausentes do escritório que para os presentes. Os trabalhadores, assim, trocam uma forma de submissão ao poder — cara 
a cara - por outra, eletrônica; A microadministração do tempo avança rapidamente, mesmo quando o tempo parece desregulado em comparação com os males da fábrica de alfinetes de Smith ou o fordismo. A "lógica métrica" do tempo de Daniel Bell passou do relógio de ponto para a tela do computador. $\mathrm{O}$ trabalho é fisicamente descentralizado, o poder sobre o trabalhador mais direto. Trabalhar em casa é a ilha última do novo regime" (Sennett, 2009, p. 68).

A cobrança é implícita e passa por meio psicológico. A liberdade nesse formato de trabalho é aparente e enganosa. O trabalhador ao mesmo tempo, sente-se honrado, privilegiado por fazer se sentir incluído nesse jogo organizacional, mas ao mesmo tempo vivencia conflitos entre a cobrança excessiva e muitas vezes velada e por uma culpa caso não responda aos resultados esperados.

Nesse novo regime econômico, a coerção no mundo do trabalho não acabou e pelo contrário, ganhou força. Mas aparece através de outras formas de gestão empresarial as quais vão exercer controle de maneira menos direta, já que não tem mais cobrança face a face no cotidiano dos trabalhadores (Boltanski \& Chiapello, 2009). Assim, o desemprego, a diminuição da garantia de empregos, o trabalho temporário ou por prazo determinado ganham forças para serem utilizados como formas de instigação e coerção, pontos vistos fortemente nos dias de hoje.

Correr risco é outra característica da nova ética do trabalho. Assim como trabalhar em equipe e estar na dinâmica do curto prazo, correr risco é mais uma narrativa do discurso flexível que é disseminado como virtude. Neste contexto, de acordo com Sennett (2009), os jovens ganham espaços já que nesse discurso, eles têm mais abertura para mudança e mais facilidade a essa submissão. A geração de meia idade, sente-se que esse sistema aniquila a sua identidade em que se sente obrigada a se adaptar de acordo com esse novo regime, tendo que anular suas raízes, suas origens. As novas formas de trabalho fomentam o risco, uma vez que são estruturadas por projetos, com início, meio e fim, de maneira que o trabalhador terá que se movimentar a procurar novos projetos. Correr risco, então, implica em assumir e buscar constantemente novos caminhos, novos projetos sem caminhos previamente definidos.

Todos estes novos comportamentos discutidos até aqui, a transformações dos valores obtidos na sociedade moderna, o tempo que não volta mais, as novas exigências do mercado flexível, a nova ética do trabalho, as novas relações de trabalho podem ser entendidas como temas geradores de um sofrimento psíquico. Um sofrimento nesse novo sujeito social que vivencia um conflito em responder às expectativas dessa sociedade e uma busca incessantemente de não ser excluído do mercado de trabalho e do seu meio social. E para fomentação dessas ideologias, o modelo flexível traz um discurso engajador, de maneira que o trabalhador necessita e luta internamente para se manter dentro desse sistema.

A palavra "flexibilidade" entrou na língua inglesa no século quinze. Seu sentido derivou originalmente da simples observação de que, embora a árvore se dobrasse ao vento, seus galhos sempre voltavam à posição normal. "Flexibilidade" designa essa capacidade de ceder e recuperar-se da árvore, o teste e restauração de sua forma. Em termos ideais, o comportamento humano flexível deve ter a mesma força tênsil: ser adaptável a circunstâncias variáveis, mas não quebrado por elas. A sociedade hoje busca meios de destruir os males da rotina com a criação de instituições mais flexíveis. As práticas de flexibilidade, porém, concentram-se mais nas forças que dobram as pessoas (Sennett, 2009, p. 53). 
Há uma tensão que inquieta o sujeito social contemporâneo. Essa tensão, segundo esses autores, advém do paradoxo da exigência de ser alguém e ser flexível. Ser alguém, nesse novo mundo, é ser um sujeito cheio de especificidade que traduzem em comportamentos flexíveis de acordo com um tipo "ideal" de ser bemsucedido, um homem de sucesso, como aponta Sennett (2009). É esse fato que marca a subjetividade desse sujeito e traz um sofrimento latente no seu eu. A luta interna do sujeito para manter preservados os princípios éticos citados e o engajamento para o mercado flexível vão traduzir no "mal-estar contemporâneo", nova marca desse sujeito social, o trabalhador contemporâneo.

Com a nova ordem do capitalis mo de ser flexível a todo custo, o sujeito social contemporâneo percebe a ruptura com suas raízes mais profundas que se relacionam e passa a se questionar sobre a indifere nça que o próprio sistema produz, afinal "Quem precisa de mim?" (Sennett, 2009, p. 174.)

Assim, a seguir apresentamos quais os recursos metodológicos foram utilizados para chegarmos à discussão da temática apresentada.

\section{Metodologia de Trabalho}

A proposta desta seção é apresentar a caracterização do objeto de investigação, a origem das fontes dos dados pesquisados e o método de análise desenvolvido. Dessa forma, se terá uma descrição dos passos metodológicos seguidos, os quais garantiram a consistência científica da pesquisa realizada.

\section{Caracterizando o objeto de pesquisa e o sujeito social pesquisado}

O objeto de investigação dessa pesquisa é uma empresa privada, localizada no estado do Tocantins, pertencente a um grupo empresarial brasileiro. No ano de 2014, esta empresa obteve a concessão do Governo Federal para prestação de serviços de utilidade pública no estado do Tocantins. Neste período apresentou um quadro de 861 empregados próprios e 1750 empregados terceirizados em todo o estado. Em 2016, ano da realização dessa pesquisa, a empresa apresentou um quadro de pessoal de 1315 empregados e 1747 terceiros. Após assumir o controle acionário da empresa, a gestão da empresa realizou uma reestruturação organizacional na qual englobava desde mudanças na estrutura de pessoal até a mudança de processos, envolvendo altos investimentos em novas tecnologias, em imagem e na nova marca da empresa.

Os sujeitos sociais dessa pesquisa foram os empregados da empresa referida, classificados em 3 (três) grupos: GA empregados pertencentes ao nível intermediário, o qual se refere aos cargos de engenheiros, analistas, gerentes, coordenadores, diretores. GB - empregados do nível de supervisão e execução e GC membro do sindicato. Para preservação da identidade dos entrevistados, esses foram identificados de acordo com o grupo que definia suas posições hierárquicas na estrutura organizacional, tais como GA1, GA2, GB1, GB2, GC1 e assim sucessivamente.

\section{Recursos metodológicos}

A investigação social proposta por Quivy e Campenhoudt (1992) foi utilizada como método dessa pesquisa. Foi necessário se aproximar do objeto de pesquisa, mas ao mesmo tempo estar fora da relação com esse, como define a investigação social. Quivy e Campenhoudt (1992) expõem que a investigação social é comparável às pesquisas em áreas exatas. Para esse autor, o investigador também vai se deparar com o real e para isso terá um método de trabalho com uma ordem lógica de procedimentos. 
A partir dessa premissa, criou-se um cronograma de trabalho para realização dessa pesquisa, conforme descrição a seguir: pesquisa bibliográfica sobre o setor pesquisado no Brasil e sobre a empresa em questão, elaboração da carta de autorização de realização da pesquisa, solicitação de autorização da pesquisa via e-mail, contato com a empresa via e-mail e telefone para que descrevesse sobre como seria o trabalho, visita à empresa, levantamento de documentos internos e externos, entrevis tas na empresa com seus empregados, entrevista com o membro do sindicato e análise dos dados.

Este tipo de pesquisa também é conhecido como pesquisa qualitativa. Segundo Godoy (1995, p. 21), a pesquisa qualitativa pode ser melhor entendida como um fenômeno compreendido no contexto onde ocorre e sendo que faz parte e está inserido. Esta deve ser analisada de maneira integral, ou seja, devem-se considerar todos os campos de vista relevantes. É importante salientar que essa ordem foi flexível e em muitos momentos, a coleta de documentação sobre a empresa foi concomitante às demais etapas, mesmo existindo uma ordem cronológica de procedimentos proposta pela investigação social. Essa flexibilidade foi permitida baseada no conceito de Godoy (1995), ao afirmar que a proposta da pesquisa qualitativa não é uma estrutura rígida.

A coleta de dados foi realizada em diversas fontes a partir do conceito da pesquisa documental, trazido por Godoy (1995) o qual pode ser entendido como o exame de materiais de natureza diversas buscando interpretações complementares. Estes documentos podem ser jornais, revistas, diários, obras literárias, científicas e técnicas, cartas, memorandos e relatórios as estatísticas e os elementos iconográficos. Se produzidos por quem está pesquisando, serão denominados como dados primários e se produzidos por pessoas que não estavam presentes na ocorrência do evento serão denominados secundários. Assim, a pesquisa documental visou identificar o que existe produzido em livros, teses, artigos, leis, revistas, cartilhas entre outros, sobre o tema pesquisado. Dessa forma este trabalho teve como fonte de dados documentação externa e documentação interna, como jornais, revistas, folders produzidos pela própria empresa.

Além da pesquisa documental, outro passo da pesquisa foi a realização de entrevistas com os sujeitos sociais pesquisados. Baseado na investigação social, esta etapa se divide em 2 (duas) fases: entrevista exploratória ou de sondagem e entrevista em profundidade, de acordo com Quivy e Campenhoudt (1992). As entrevistas de sondagem ou exploração podem ser entendidas como um tipo de entrevista não diretiva que faz parte da etapa de exploração. Esse tipo de técnica deu o suporte para o aprofundamento da investigação, que segundo Quivy e Campenhoudt (1992), é imprescindível para prosseguir com a pesquisa focando na problematização.

Nesta fase, pôde-se conhecer os cargos estratégicos da empresa e desenhar uma proposta sequencial de pessoas chaves a serem entrevistadas e ao mesmo tempo solicitar a indicação de próximos entrevistados, por esses que passaram pelas entrevistas. Assim, a busca por esses sujeitos entrevistados partiu da teoria da Bola de Neve (Baldin \& Munhoz, 2011), quando se trata da definição das pessoas chaves e posterior, o entrevistado indica outro entrevistado e esse outro indica mais outro e assim sucessivamente. Nesta etapa, 3 (três) entrevistas de sondagem foram realizadas.

O passo seguinte, foi a entrevista de profundidade ou semi-dirigida, cujo objetivo, segundo Quivy e Campenhoudt (1992), é analisar o sentido que os entrevistados dão à sua realidade cotidiana e confrontar com um sistema de crenças e valores onde estão inseridos esses sujeitos sociais pesquisados. Este tipo de entrevista possibilita analisar os jogos e relações de uma organização, e possibilita a reconstrução de fatos e acontecimentos. 
Dessa feita, este método possibilitou uma maior aproximação da investigação social.

Nas suas diferentes formas,
distinguem-se pela aplicação dos
processos fundamentais de
comunicação e de interação humana.
Corretamente valorizados, estes
processos permitem ao investigador
retirar das suas entrevistas
informações e elementos de reflexão
muito ricos e matizados. Ao contrário
do inquérito por questionário, os
métodos de entrevista caracterizam-se
um contato direto entre o investigador
e os seus interlocutores e por uma
fraca diretividade por parte daquele
(Quivy \& Campenhoudt, 1992, p.
193).

Pode-se entender com essa afirmação que a entrevista semi-dirigida ou de profundidade é uma troca entre o investigador e o interlocutor. Assim, as percepções podem ser colocadas nessa fase, o que será de grande importância na análise dos dados. A partir desse aporte teórico da entrevista semi-dirigida, um roteiro norteador foi construído para apoio à pesquisa. Esse roteiro serviu para orientação quanto ao objetivo. Sendo assim, ao iniciar a entrevista, era apresentado ao entrevistado um panorama da pesquisa e o que gostaria de identificar naquela conversa como sua origem, estado civil, idade, cargo, como era a empresa na gestão anterior e na atual, quais eram os pontos que se assemelhavam e o que mudou, expectativas, formas de controle, valores que a empresa preza, por exemplo. Assim após explanação, era falado sobre o Termo de Consentimento Livre Esclarecido, momento que foi colhido a assinatura do entrevistado.

Nesta etapa foram realizadas mais 9 (nove) entrevistas, no período de junho a dezembro de 2016 com objetivo de aproximar da problemática da pesquisa. Dessas 9 (nove), 8 (oito) foram realizadas com os trabalhadores da empresa e 1 (um) com um membro do sindicato dos trabalhadores. Das 8 (oito) entrevistas com os empregados da empresa, 3 (três) representavam o nível operacional.

Para se ter uma visão global, buscou-se contatar ex-empregados da empresa, os quais se desligaram na mudança de gestão. Esses ex-empregados foram indicados pelo sindicato. Porém, dos 5 (cinco) contatos realizados, 2 (dois) não tiveram interesse, 1 (um) não deu retorno e 2 (dois) marcaram e não compareceram à entrevista.

Diante dessa situação, optou-se por findar as entrevistas somente com os empregados do quadro atual e o membro do sindicato, totalizando com a realização de 12 (doze) entrevistas durante todo este processo. Encerrou-se as entrevistas com o ponto de saturação, onde as informações dos entrevistados passaram a se repetir, sem conteúdo novo para ser acrescido, conforme conceito de Baldin e Munhoz (2011).

O próximo passo foi a análise qualitativa das entrevistas em profundidade e dados coletados, conforme Thiollent (1992), a qual parte do pressuposto que todo conteúdo produzido em uma entrevista tem uma significação. Thiollent (1992, p. 202) afirma que "todo indivíduo é portador de cultura e subcultura às quais pertence e que é representativo dela. As produções advindas de uma entrevista em profundidade são reveladoras de um conjunto de representação, tais como: símbolos, hábitos, valores que os representam".

Partindo dessa afirmação, este método tem por objetivo apreender o mundo produzido pelo sujeito entrevistado de maneira que o entrevistador possa reconstituir os mundos sociais existentes. Como procedimento dessa análise, o material foi analisado a partir de leituras e releituras do material produzido. Dessa forma, descreve Thiollent (1992), que com este método haverá uma "impregnação" dos sentidos do fato pesquisado, de maneira a buscar interações entre as entrevistas 
realizadas, possibilitando prosseguir para a interpretação dos sentidos.

As entrevistas foram transcritas e em seguida, todas as produções dos entrevistados foram organizadas em uma planilha para que pudessem ser interpretados, após a "impregnação" dos dados. A interpretação das informações, proposta por Thiollent (1992), deve buscar relações entre si nas entrevistas e nos dados coletados.

\section{Resultados e discussões}

A partir dos relatos dos entrevistados e dos documentos coletados definiu-se as seguintes categorias a serem analisadas: traços da nova ética do trabalho, disseminação da nova ética do trabalho e sofrimento psíquico do trabalhador.

Registros da nova ética do trabalho foram encontrados a partir de traços organizacionais como um discurso de adaptação, busca por excelência e a necessidade de contração do tempo.

A necessidade de adaptação é identificada conforme se revela no discurso a seguir. "A gente, na verdade é o que eu falo, a gente tem que se adaptar, a resiliência é essencial" (GA7). A busca por excelência é um traço que foi identificado nos relatos, demonstrando um tipo de sofrimento provocado pela nova ética do trabalho. A necessidade dessa busca, muitas vezes desenfreada, é internalizada pelo trabalhador e se faz presente em sua rotina na busca de desenvolver comportamentos ideais e exemplares.

O $2^{\circ}$ passo, no próprio dia a dia [...] no nosso time aqui, se eu estou falando que sou focado em cliente, então eu tenho que fazer um bom atendimento, eu tenho que dizer um não e justificar porque estou dizendo aquele não, não é dizer sim o tempo inteiro para o cliente, mas sim aquilo que eu posso fazer. [...] Na verdade, digamos que é uma cadeia de exemplos. Eu vou te citar um exemplo: o nosso diretor presidente, ele é o presidente da Cipa.[...] É como que nós somos cobrados nisso? Primeiramente pelas atitudes, eu observo isso [...] Então, são essas atitudes nossas, somos cobrados em pequenas atitudes do dia a dia, no gerenciar as nossas pessoas, no tratar as pessoas que estão conosco, seja cliente, não precisa ser o cliente consumidor, mas o cliente, como você mesmo que está aqui comigo necessitando de uma ajuda para dar sequência ao seu trabalho. Então, são pequenas atitudes assim, que no nosso dia a dia. (GA4).

No relato acima, é possível observar a busca por esta "excelência" no dia a dia dos empregados, nas atitudes cotidianas. Esta "excelência" é controlada pelos resultados de cada um. A nova ética profissional define os passos do trabalhador, segundo Sennett (2009). Um olhar invisível controla cada passo. 'Desde que a pessoa entra na empresa até o momento que ela sai, a gente está observando muito estes valores e comportamentos" (GA4).

$\mathrm{O}$ reinado do tempo, a valorização de sua contração é identificada no cotidiano dos entrevistados. O empregado que ocupa o seu tempo ou é solicitado a todo momento ganha pontos, ganha status nessa nova ética do trabalho. São comportamentos reforçados dentro de uma empresa.

Às vezes no final de semana tem uma dúvida aqui e eles ligam, se tem um acidente a gente é envolvido também. À noite as vezes surge alguma dúvida, algo importante, eles me ligam, mas não é uma frequência assim, é muito mais no dia a dia. No dia a dia, é toda a hora. Toda hora praticamente a gente tá fazendo um trabalho, como área de consultoria, na rotina. Não tem jeito, todo dia tem. (GA4).

O aproveitamento do tempo com novas tecnologias é visto na fala do 
entrevistado a seguir: "Hoje como mudou o sistema, com smartphone você faz toda solicitação de serviço, acompanha. Um salto de qualidade muito grande. Eles têm tecnologia" (GA2). Há uma inculcação da nova ética que o faz acreditar que ter tecnologia é sinônimo de qualidade, velando o reinado da urgência do tempo.

A disseminação da nova ética do trabalho é outra categoria que foi analisada. A instigação ou inculcação discutida por Weber (1967) e Boltanski e Chiapello (2009) para se engajar no trabalho foi identificada no uso de gramáticas com vocábulos que fomentam a disciplina, o self made man e a concepção de ser feliz, "homem de sucesso", na sociedade contemporânea.

De acordo com os relatos de entrevistas e com a ampla divulgação na mídia interna e externa, observou-se que a empresa apresenta altos investimentos em mecanismos para fomentar a ideologia de uma adaptação do trabalhador ao mercado flexível.

O discurso é bem diferente. Pra quem não conhece, pra quem tá de fora, olhando as ações deles na mídia externo e interno, também tem uma impressão de uma empresa que preocupa com os trabalhadores, preocupa com a sociedade, um grupo que explora muito a imagem dela. Ela tenta passar pro público interno e externo como sendo uma empresa com responsabilidade enorme. Eles investem em tudo quanto é tipo de mídia. (GC1).

Uma série mensal de publicações dos jornais internos da empresa revelaram este tipo de instigação, podendo ser observados a partir das tabelas apresentadas a seguir. As tabelas foram organizadas a partir de gramáticas utilizadas com conteúdo mobilizador para engajamento no trabalho, sendo dividida em 4 (quatro) partes a fim de designar a mensagem analisada, especificando o veículo de comunicação utilizado e localização da mensagem a partir da edição e seção indicada do jornal analisado.

Tabela 1- Gramáticas utilizadas em jornais internos da empresa

\begin{tabular}{c|c|c|c}
\hline MENSAGEM & $\begin{array}{c}\text { VEÍCULO DE } \\
\text { COMUNICAÇÃo }\end{array}$ & EDIÇÃo & SEÇÃO \\
\hline $\begin{array}{c}\text { Disciplina é a chave para } \\
\text { alcançar resultados }\end{array}$ & Jornal Interno & $\begin{array}{c}\text { Ano 1. No9 Edição } \\
\text { Especial 1 ano de } \\
\text { integração }\end{array}$ & Resultado \\
\hline $\begin{array}{c}\text { A evolução começa em } \\
\text { você }\end{array}$ & Jornal Interno & Ano 2. N N $^{\circ}$ 15. Dez 2015 & Panorama \\
\hline $\begin{array}{c}\text { Educar para crescer, ser } \\
\text { produtivo e feliz }\end{array}$ & Jornal Interno & Ano 2. N N $^{\circ}$ 16. Jan 2016 & Capa \\
\hline
\end{tabular}

Fonte: Elaborada pelas autoras (2017).

Como discutido por Sennett (2009), os temas descritos como disciplina, evolução, educar, ser produtivo, ser feliz faz parte de um corpus de palavras que representam a nova ética do trabalho.

O tema da "autonomia" é verific ado também na exposição dos jornais internos da empresa. A aparente autonomia também é uma forma de engajar os empregados no trabalho, conforme discussão de Boltanski e Chiapello (2009), os quais destacam que essa é aparente por estar definida nos procedimentos e descrição de cargos de uma empresa. 


\begin{tabular}{c|c|c|c}
\hline MENSAGEM & $\begin{array}{c}\text { VEÍCULO DE } \\
\text { COMUNICAÇÃO }\end{array}$ & EDIÇÃO & SEÇÃO \\
\hline $\begin{array}{l}\text { Antes a gente fazia só o que o líder da } \\
\text { Unidade de Serviço (US) nos } \\
\text { encaminhava. Agora temos autonomia } \\
\text { e não precisamos esperar por ninguém } \\
\text { para resolver um problema na rede(...) }\end{array}$ & & Jornal Interno 2. n16. jan 2016 & Boa Ideia \\
\hline
\end{tabular}

Fonte: Elaborada pelas autoras (2017)

A naturalização do risco é fomentada no cotidiano dos trabalhadores por diversos meios e ganha força quando é disseminada por jornais, como observado em uma carta do diretor presidente em um jornal da empresa, conforme apresentado na Tabela 3. Esta é uma estratégia com forte potencial de alcance a todos os empregados da empresa.

Tabela 3 - Convite ao Risco - Carta do Presidente

\begin{tabular}{|c|c|c|c|}
\hline CHAMADA & $\begin{array}{c}\text { VEÍCULO DE } \\
\text { COMUNICAÇÃO }\end{array}$ & EDIÇÃO & SEÇÃO \\
\hline $\begin{array}{l}\text { (...)que você seja o } \\
\text { protagonista dessa obra! } \\
\text { Que você se dedique a } \\
\text { construí-lo junto } \\
\text { conosco a partir do seu } \\
\text { entusiasmo e } \\
\text { comprometimento. Para } \\
\text { isso, espero que você se } \\
\text { arrisque mais, se atreva } \\
\text { mais, se incomode mais } \\
\text { com tudo aquilo que } \\
\text { entenda que possa ser } \\
\text { melhorado e não tenha } \\
\text { medo de errar. Atue } \\
\text { fortemente para permitir } \\
\text { a transformação que } \\
\text { queremos para nossa } \\
\text { empresa e para toda } \\
\text { sociedade que nos cerca. }\end{array}$ & Jornal Interno & Ano 2. n16. jan 2016 & $\begin{array}{l}\text { Carta ao Colaborador- } \\
\text { assinada pelo diretor- } \\
\text { presidente }\end{array}$ \\
\hline
\end{tabular}

Fonte: Elaborada pelas autoras (2017)

O risco passa a fazer parte do cotidiano dos trabalhadores como algo normal e comum, já que a rotina desapareceu dando lugar à instabilidade e imprevisibilidade.

Como aliado das ideias dos jornais, a consultoria, discutida por Donadone (2005) também foi apresentada como fomentadora desse engajamento. Assim, para mobilizar os trabalhadores a desenvolverem trabalho em equipe, para "desenvolver as pessoas", termo usado pelos sujeitos entrevistados, as empresas de consultorias têm forte papel nessa instigação.

Aí entra o trabalho que é o desenvolvimento dos líderes que a gente também faz. É a academia de líderes, que são vários módulos em que a gente vai moldando as pessoas. Nós fazemos in company, a gente contrata a consultoria, montamos as turmas, isso em todas as empresas do grupo. Inclusive esses módulos são realizados, foram desenvolvidos já olhando para os valores, já pautando 
em clientes, resultados, pessoas. (GA4).

Finda-se essa análise com a discussão da categoria sofrimento psíquico do trabalhador. Observamos que a nova ética do trabalho produz um sofrimento no sujeito social contemporâneo. As entrevistas revelaram o sofrimento vivido pelo trabalhador na atualidade. Um sofrimento que descreve uma ruptura com sua identidade reduzindo às condições de uma estrutura do mercado.

Mas a empresa alega que é o processo de reestruturação. Ela tá colocando as peças do jeito que ela deseja, né, mas realmente, principalmente esse semestre, né. Esse ano mesmo, se não me falha a memória, deve ter tido umas 70 demissões, então, né. Eu não sei o percentual, mas boa parte do percentual, digamos assim, tem também algumas áreas que foram reestruturadas corporativamente, né. Então, teve umas baixas nesse sentido mesmo, alguns processos foram otimizados para todo grupo. Teve a dispensa de várias pessoas. (GA6).

Olha, nós fizemos aqui um levantamento, até setembro, pro cê ter uma ideia, a empresa tinha dispensado 70 trabalhadores. Todos eles substituídos por pessoas menos experiente, não é que a empresa tem reduzido o quadro, ela está substituindo a mão de obra por pessoas menos experientes e com salário muito menor. (GC1).

A situação revelada nas falas anteriores, reflete o que Birman (2012) descreve ao dizer que o sujeito na atualidade é reduzido e estruturado de acordo as condições de mercado e bens e serviço, na qual vai refletir em uma nova forma de relacionar se com o tempo, com o espaço e com o trabalho. Essas são as marcas da nova subjetividade. A certeza, a previsibilidade, a estabilidade do emprego e das práticas de trabalho se romperam e esse rompimento causa também sofrimento no trabalhador, como discutido em Birman (2012).

A autoestima desqualificada e a desvalorização de si mesmo trazem a sensações de vazio para o dia a dia do trabalhador, esvaziando o sentimento de certeza de ser em sua totalidade, conforme relato a seguir.

E quando veio a [a empresa], aí é outra coisa. Tem que mostrar quem você é como profissional, mostrar quem você é como profissional, porque você não tá ali simplesmente por estar, mostrar também que você tem conhecimento, mas ao mesmo tempo, pelo ao menos assim, nas nossas áreas nós tivemos um grande bloqueio das que são chamadas [externas], porque pra nós ficamos de certa forma estigmatizados, por terem sido empresas que [...] tinham problemas. (GA7).

A chegada de um grupo novo obriga o empregado a enfrentar sua intimidade, fazendo com que exponha a sua autoimagem, conforme demonstrado no relado anterior. Assim, "o sentimento de segurança psíquica, isto é, de que o eu pode dar conta das relações entre o corpo e o mundo, se esvazia de maneira flagrante. $\mathrm{O}$ eu e o psiquismo perdem efetivamente a sua potência" (Birman, 2012, p. 117). Esse esvaziamento do sujeito, com o sentimento da perda da sua totalidade é visto como o "mal-estar contemporâneo".

Esse "mal-estar" é revelado através do relato que demonstra esta necessidade de se adaptar a todo tempo em todos os âmbitos da sua vida.

A gente, na verdade é o que eu falo, a gente tem que se adaptar, a resiliência é essencial, o mundo tá em transformação, não é só na vida profissional, na vida pessoal, todas as 
áreas da vida, a gente tem sempre transformação. E é receber sempre pensando que vai ser positivo, entendeu, receber que vai ser sempre positivo. (GA7).

Outra contribuição que reflete em sofrimento e conflito interno, diz respeito a autonomia, excesso de cobrança e culpa em não dar conta do resultado e instabilidade, sintomas do "mal-estar contemporâneo". A chegada de um grupo novo nos revela esta instabilidade para os empregados.

A partir do momento que entrou a [empresa nova], nós éramos todos novos, por mais que a gente tinha toda uma experiência, todo $\mathrm{O}$ conhecimento da empresa, eu já tava aí com 12, 13 anos de empresa, o tratamento era como se a gente tivesse sido contratado naquele momento, né, que era notório isso, né. Porque com certeza, eles vinham pra poder implantar a cultura dele e trazer o pessoal dele. (GA7).

O tempo de trabalho já não é mais valorizado. A experiência pode até mesmo ser um entrave à mudança nesse novo regime flexível, trazendo um sofrimento ao trabalhador. No relato abaixo é possível identificar um conflito quando o sujeito declara que teve um impasse para empresa que chegou a aceitar quem estava no local, aceitar o seu conhecimento e tempo de serviço.

Eu acho que a maior dificuldade foi a questão dos impasses mesmo assim [das externas] com as adquiridas, entendeu. A questão assim, eu tenho o meu espaço também, não é só uma questão de só impor. E como é uma empresa familiar é muito dessa visão. Não é o do comprar, vamos ver o que é melhor juntos. O meu é o certo, nós que compramos vocês, então assim, no início foi bem difícil. [...]. Então assim, foi um impasse muito grande no início, por essa questão de, havia por ali de certa forma uma corda bamba, e que olha, nós estamos aqui não é por um acaso. Nós também temos um conhecimento, entendeu? (GA7).

Fatores como possibilidade de demissão, imprevisibilidade de um futuro, cobrança excessiva, instabilidade na carreira e desvalorização da experiência são componentes que refletem na subjetividade do trabalhador provocando um sofrimento psíquico nesse sujeito social.

\section{Considerações Finais}

Este estudo apresenta limitações, mas pode oferecer um maior entendimento de como os novos dispositivos da gestão empresarial são utilizados e como provoca marcas na subjetividade do trabalhador contemporâneo, inclusive causando um sofrimento psíquico nesses sujeitos. Observa-se que esses dispositivos atuam de forma muito eficaz e muito profunda para um engajamento completo, indo no íntimo das pessoas de maneira que se entreguem ao trabalho de corpo e alma. É uma nova estratégia, "a instrumentalização e a mercadização dos homens naquilo que eles têm de propriamente humano" (Boltanski \& Chiapello, 2009, p. 471). Esses dispositivos vão trabalhar exatamente na moral do ser humano, onde ganhará força para se perpetuar, já que o sujeito inculcado nas ideologias do tipo- ideal discutido por Weber (1967), não consegue mais romper com o sistema, por receio, medo ou angústia de se sentir excluído, sendo incapaz de criar o seu próprio sentido.

Nessa nova ética, as relações são imediatas, fugaz e com pouco compromisso. As pessoas são descartáveis visto nas práticas das reengenharias. Assim, esse sujeito sente-se também mais um nesse processo e que pode ser descartável a qualquer momento, se tiver meia idade ou se não ritualizar às práticas sugeridas pela nova ética do trabalho. E é essa incerteza, 
esse descarte, essa falsa adaptação que marca $o$ sofrimento do trabalhador contemporâneo.

Portanto, para um maior entendimento de quem é o trabalhador contemporâneo e que tipo de sofrimento ele vive atualmente é necessário buscar conhecer o regime econômico vigente. Dessa forma, é possível compreender as formas disseminadas para capturar $o$ trabalhador contemporâneo, as quais provocam marcas profundas em sua subjetividade.

\section{Referências}

Baldin, N., \& Munhoz, E. Snowball (2011). (Bola de Neve): Uma Técnica Metodológica para Pesquisa em Educação Ambiental Comunitaria. I Seminário Internacional de Representações Sociais, Subjetividade e Educação - SIRSSE. PUC - Curitiba.

Boltanski, L., \& Chiapello, E. Le. (2009). $O$ novo espírito do capitalismo. Tradução Ivone C. Benedetti. Umf martinsfontes. São Paulo.

Birman, J. (2012). $O$ sujeito na contemporaneidade: espaço, dor e desalento na atualidade / Joel Birman. - Rio de Janeiro: Civilização Brasileira.

Brasil. Ministério da Saúde. (2001). Transtornos mentais $e$ do comportamento relacionado ao trabalho. In: BRASIL. Ministério da Saúde. Doenças relacionadas ao trabalho: manual de procedimentos para serviço de saúde. Brasília. Ministério da Saúde, (pp. 161-194). Recuperado de http://bvsms.saude.gov.br/bvs/public acoes/partes/doencas_trabalho1.pdf

Cardoso, A. (2007). Tempos de trabalho, tempos de não trabalho. Tese Departamento de Sociologia e Faculdade de Filosofia, Letras e Ciências Humana - Universidade de
São Paulo. São Paulo. Recuperado de http://www.teses.usp.br/teses/disponi veis/8/8132/tde-20032008101721/pt-br.php

Dedord, G. (2003). A sociedade do espetáculo. Tradução em português: www.terravista.pt/Ilhadomel/1540. $2003 . \quad$ Recuperado de http://www.ebooksbrasil.org/adobeeb ook/socespetaculo.pdf

Donadone, J. (2005). Consultoria internacional em expansão e formas emergentes de globalização das trocas e contenciosos gerenciais. Tempo Social, revista de sociologia da USP. (Vol, 22, n. 1). Recuperado de http://www.scielo.br/pdf/ts/v22n1/v22n 1a06.pdf

Ewald, P,. \& Soares, C. (2007). Identidade e subjetividade numa era de incerteza. Estudos de Psicologia, (Vol. 12 (1), pp. 23-30). Universidade do Rio de Janeiro.

Godoy, A. (1995). A pesquisa qualitativa e sua utilização em administração de empresas. Revista de administração de empresas, São Paulo/SP.

Harvey, D. (1996). Condição pós-moderna: uma pesquisa sobre as origens da mudança cultural. São Paulo: Loyola.

Mariano, R. (1996). Os novos pentecostais e a teologia da prosperidade. Novos Estudos CEBRAP. (Vol. N. $\left.{ }^{\circ} 44\right)$. Recuperado de http://novosestudos.org.br/v1/files/up loads/contents/78/20080626_os_neo pentecostais.pdf

Menchise, R. (2014). Sebrae entre a foice e o martelo: uma discussão sobre a metamorfose dos trabalhadores em empresários. Coninter 3 - Congresso Internacional Interdisciplinar em Sociais e Humanidades. Salvador BA. ISSN 2316 - 266X, n.3. (Vol. 2, pp. 697-717). Recuperado de http://aninter.com.br/Anais \%20CON INTER\%203/GT\%2002/44.\%20ME NCHISE.pdf

Quivy, R., \& Campenhoudt, L. (1992). Manual de investigação em ciências 
sociais. Tradução de João Minhoto

Marquese e Maria Mália Mendes.

Editora: Gravida.

Sennett, R. (2009). A Corrosão do Caráter: consequências pessoais do trabalho no novo capitalismo / Richard Sennett: tradução Marcos Santarrita, $14^{\circ}$ ed. - Rio de Janeiro: Record.

Thiollent, M. (1992). Crítica metodológica, investigação social e enquete operária. /M. Thiollent. Capítulo III: $\mathrm{O}$ processo de Entrevista. Editora Polis. São Paulo.

Weber, M. (1967). A ética protestante e o espírito do capitalismo. São Paulo: Pioneira.

Data de submissão: 27/07/2017

Data de aceite: 20/08/2017 